\title{
In silico modeling of toluene binding site in the pore of voltage-gate sodium channel
}

\author{
Thomas RF Scior' \\ Evelyn Martínez-Morales ${ }^{2}$ \\ Silvia L Cruz \\ Eduardo M Salinas-Stefanon ${ }^{2}$ \\ 'Departamento de Farmacia; ${ }^{2}$ Instituto \\ de Fisiología, Benemérita Universidad \\ Autónoma de Puebla, Ciudad \\ Universitaria,Puebla, Pue, México; \\ ${ }^{3}$ Departamento de Farmacobiología, \\ CINVESTAV-IPN, Calz. Col. Granjas \\ Coapa, México
}

Correspondence: Eduardo M Salinas-Stefanon Instituto de Fisiología, B Universidad Autónoma de Puebla, Av I4 Sur, Col San Manuel, Puebla, Pue, México, 72501 Tel +522222295500 Ext 7320 Fax +52 2222295500 Ext 730I Email esalinas@siu.buap.mx

\begin{abstract}
Toluene is a commonly used organic solvent in commercial products and is sometimes abused as an inhalative hallucinogen, causing arrythmogenic toxicity. At a molecular level we investigated whether a hypothetical interaction model could be devised for the reported myoand cardiotoxic effects of toluene. Three lines of computed evidence support our hypothesis on the interaction mechanism: (i) Toluene binds at the local anesthetic binding site (LABS), on the wild type (WT) but not on its F1579A mutation, confirming our experimental findings that it inhibits only the WT of skeletal muscle or cardiac isoforms ( $\mathrm{Na}_{v} 1.4$ or 1.5). (ii) Typically for small alkylaryl moiety, multiple binding modes were detected during docking. Toluene is trapped in the tryptophane-rich area at the extracellular vestibule by hydrophobic interaction, mainly $\pi-\pi$ stacking, or bound to the LABS with equal binding strength and number of solved poses, mostly by edge-to-face contacts. (iii) The computed loss of toluene binding at the LABS on the mutant model parallels clearly the observed loss of toluene effects on $\mathrm{Na}_{\mathrm{v}} 1.4$. Moreover, we inspected the complete primary sequences with the omitted loops in the 3D models to identify the possible interacting amino acids among the $16 \%$ nonidentical ones, and thus confirmed the observed toxicity effects.
\end{abstract}

Keywords: Toluene, $\mathrm{Na}^{+}$channel, $\mathrm{Na}_{\mathrm{v}} 1.4$ isoform, $\mathrm{Na}_{\mathrm{v}} 1.5$ isoform, in-silico simulation, cardiotoxicity

\section{Introduction}

Voltage-gated sodium channels underlie rapid conduction in many tissues. They are responsible for membrane depolarization and action potential conduction in heart, neuron, or skeletal muscle and constitute the biomolecular targets of many $\mathrm{Na}^{+}$ channel antagonists, either as desired therapeutic effects for antiarrhythmic drugs ${ }^{1-3}$ or as undesired side effects, eg, aminoquinolines. ${ }^{4-6}$

To the best of our knowledge, the molecular binding mode of toluene to the local anesthetic binding site (LABS) has not yet been investigated theoretically. The present in silico study has helped us to gain hypothetical insight during the last three years and parallels the seminal work on pore regions of other ion channels. ${ }^{7,8}$

The $\mathrm{Na}^{+}$channel itself is a multi-protein complex. It is divided into two types of protein subunits, alpha and beta, both of which cooperate in the regulatory functions of the channel, as well as conformational stability and changes. Our interest is in the transmembranal alpha subunit or inner pore, where the ion passage takes place. ${ }^{9}$

The target sequence of the alpha subunit encompasses four nonidentical repeats (I-IV). It is a polypeptide chain of highly lipophilic amino acids, with a total molecular weight of 190 to $250 \mathrm{kDa}$. The general fold possesses 6 transmembrane helical segments (S1 to S6) forming a cylinder. The loop segments between the last two helices (S5, S6) form not only the outer vestibule (extracellular side entrance) but also the so-called pore-loop (P-loop). The four S5-S6 segments including the P-loops of the four repeats (I-IV), embrace the central pore (Figure 1). In $\mathrm{Na}^{+}$ 


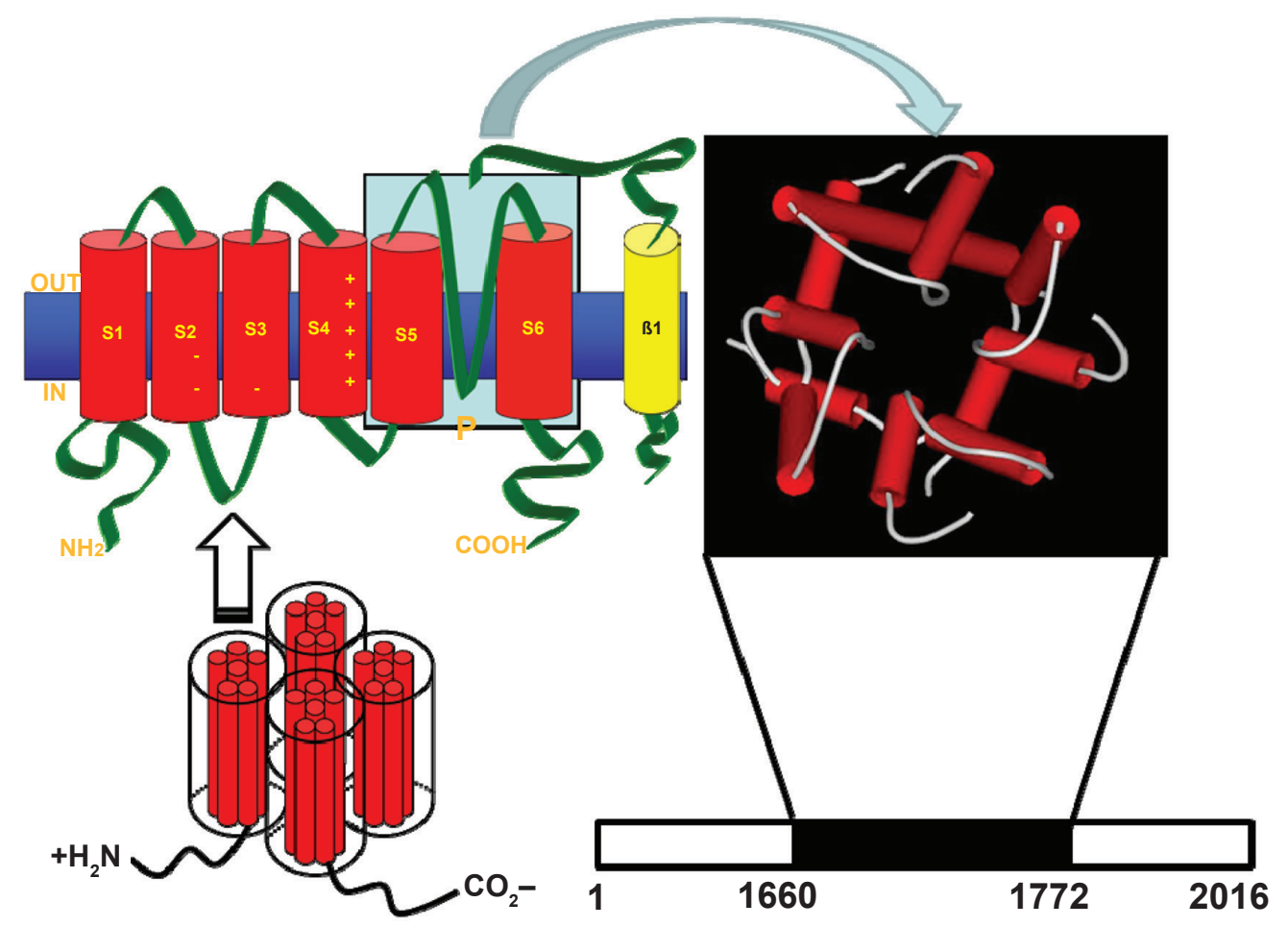

Figure I Schematic drawing of the complete sequence and display of the 3D models of the inner pore $\mathrm{Na}_{\mathrm{v}}$ I.5 with the selectivity filter (DEKA motif) of the sodium channel in the open state. The sequence starts with a low complexity (repetitive residues) segment. Three-dimensional representation (ribbon and atomic display) of essential amino acids in the pore region. The $\alpha$-helices of S5-S6 are red, the loops are white.

channels 4 conserved amino acids (I-Asp, II-Glu, III-Lys, IV-Ala) form an innermost, narrow ring, also referred to as the DEKA motif. This selectivity filter confers selective permeability to $\mathrm{Na}^{+}$ions. ${ }^{10}$

The locus composition varies sequentially and spatially according to the channel type, reflecting its function as a type-specific molecular filter to sense incoming cations which in turn differ in their ionic charges, radii, and solvation energies. Research on ion propagation through large-pore channel protein (porins such as OmpF, PhoE, WT) revealed that electric conductance of the channel is determined by the protein's form and charge distribution, whereas the features of the channel's vestibule reflect the selectivity. ${ }^{11}$ The structures of potassium alpha 1 and cytoplasmatic beta subunits were solved by crystallographic models (Table 1) and their functions discussed.

In principle, voltage-dependent ion channels open when the cell membrane is depolarized and then rapidly close by a process called inactivation. The inner pore with its central cavity forms the receptor site for small-molecule inhibitors. The cytoplasmic inactivation gate binds to the intracellular entrance and then enters the pore as an extended peptide. ${ }^{12}$ The cations are enclosed by layers of water moieties, specific to their ionic diameter and charge strength. The entrance is large enough to accommodate the cation with its water shell, but further down the backbone oxygen atoms along the channel coordinate the metal ion by replacing its shells of water molecules. Only certain cations with a specific diameter can pass through the narrow selectivity filter with a corresponding width.

An analogy can be assumed for sodium channels but the four repeats are not symmetrically arranged. The inner pore domain with the central cavity for ion passage of the voltage-dependent sodium channel in rat skeletal muscle $\left(\mathrm{Na}_{\mathrm{v}}\right.$ 1.4) has already been modeled by Tikhonov and Zhorov. ${ }^{10}$

Table I Listing of PDB-entry codes of 3D-models of ion channels at the FTP site of RCSB - Protein Data Bank (PDB at ftp.wwpdb.org)

IKYK Mechanosensitive channel from Escherichia coli in a closed state IKYM Mechanosensitive channel from Escherichia coli in an open state IS33 KcsA potassium channel in a non-conducting state breaking the fourfold symmetry

IS33 KcsA potassium channel in a non-conducting state breaking the fourfold symmetry

ISEX Voltage gated sodium channel of Anopheles gambiae

IZAS Voltage gated sodium channel (Domain II) of Anopheles gambiae

2AFL Voltage gated potassium channel $\left(K_{\mathrm{V}} \mathrm{I} . \mathrm{I}\right)$ of human 
Earlier patch clamp studies in oocytes conducted at our laboratory showed use and frequency-dependent inhibition of sodium currents by toluene. The blocking effect was complete, voltage-independent, and slowly reversible, suggesting that toluene binds to the human cardiac sodium channel in the open channel state. ${ }^{13,14}$ Thereafter, we published a study with wild type and F1579A mutant of $\mathrm{Na}_{\mathrm{v}} 1.4$, showing that this mutation at the LABS eliminates toluene effects ${ }^{14}$ (Figure 2).

Intriguing for an ion channel-blocking agent, however, the ligand under investigation, toluene, possesses neither a total charge nor polar groups and therefore cannot dissociate. In a physiological environment, as a small, nonpolar moiety $(\log \mathrm{P}=+2.3)$, it gains access to the target structure through a lipophilic pathway by direct cell permeation (passive diffusion process); because its surface is uncharged, it cannot be attracted to the open channel by sensing the electric gradient across the membrane. Hence, the cationselective DEKA motif of the pore (anionic aspartate and glutamate, cationic lysine, and neutral alanine) does not form a functional bottleneck for toluene (Figure 3, color code: magenta).

The experimental results of our electrophysiological assays with human cardiac sodium channels expressed in Xenopus oocytes and with naturally expressed cardiac channels in rat ventricular myocytes, suggest that toluene has an open-channel-blocking mechanism. An $\mathrm{IC}_{50}$ was measured as $274 \mu \mathrm{M} .^{13}$

Two lines of experimental evidence support the hypothesis for the toluene-binding site at a molecular level for the observed arrhythmogenic effect of toluene: (i) the observed inhibition of the cardiac isoform of human sodium channels $\left(\mathrm{Na}_{\mathrm{v}} 1.5\right)$ and (ii) the suppression of toluene effect on a F1579A mutant of skeletal muscle isoform $\left(\mathrm{Na}_{\mathrm{v}}\right.$ 1.4). Our published findings, already mentioned, encouraged us to perform a computed docking study to identify the possible interaction site(s) on the target structures.

\section{Methods}

\section{In silico approach}

The helical segments and loops of the target sequence in Figure 1 were predicted as a consensus line using several off-line and web-based secondary structure tools, ${ }^{15-20}$ and Expasy (http://www.expasy.ch/). The helices of the template (1LNQ, Table 2) were displayed using secondary structure profiles and the predicted helical segments of the target were threaded through the secondary structure profile of the template structure (Figure 1). ${ }^{21,22}$ The rationale behind

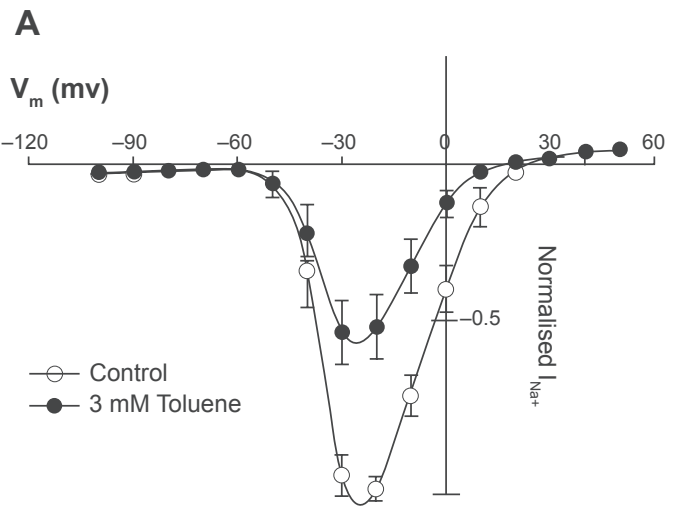

B

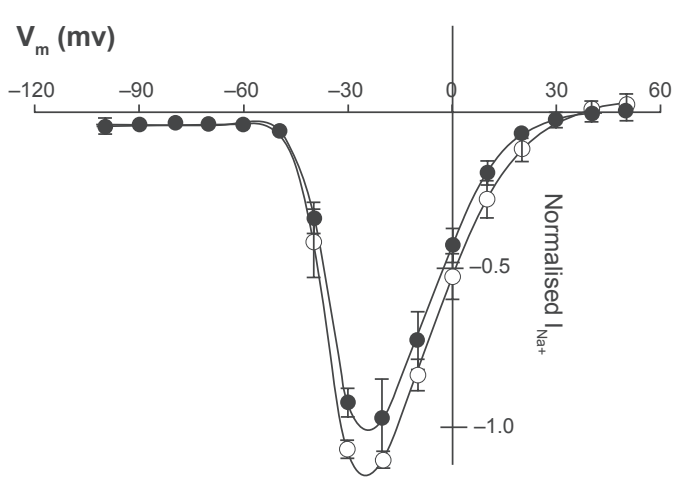

D

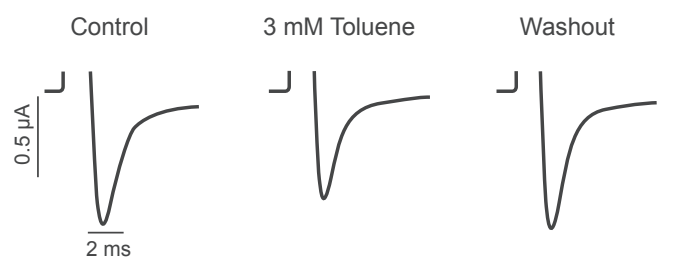

Figure 2 A and B Mean ( \pm SEM) current-voltage relationships of six oocytes from different frogs and transfected with $\mathrm{Na}_{\mathrm{v}} \mathrm{I} .4$ (left) and mutant FI579A (right) before toluene $(\circ)$ and $3 \mathrm{mM}$ toluene $(\bullet)$. C and $\mathbf{D}$, a family of whole cell $\mathrm{Na}^{+}$currents from a typical oocyte superfused with control solution (left) or $3 \mathrm{mM}$ toluene (center) and washout (right). Data shown are for test potentials between -80 and $+20 \mathrm{mV}$. Stimulation frequency was $0 . \mathrm{I} \mathrm{Hz}$. 


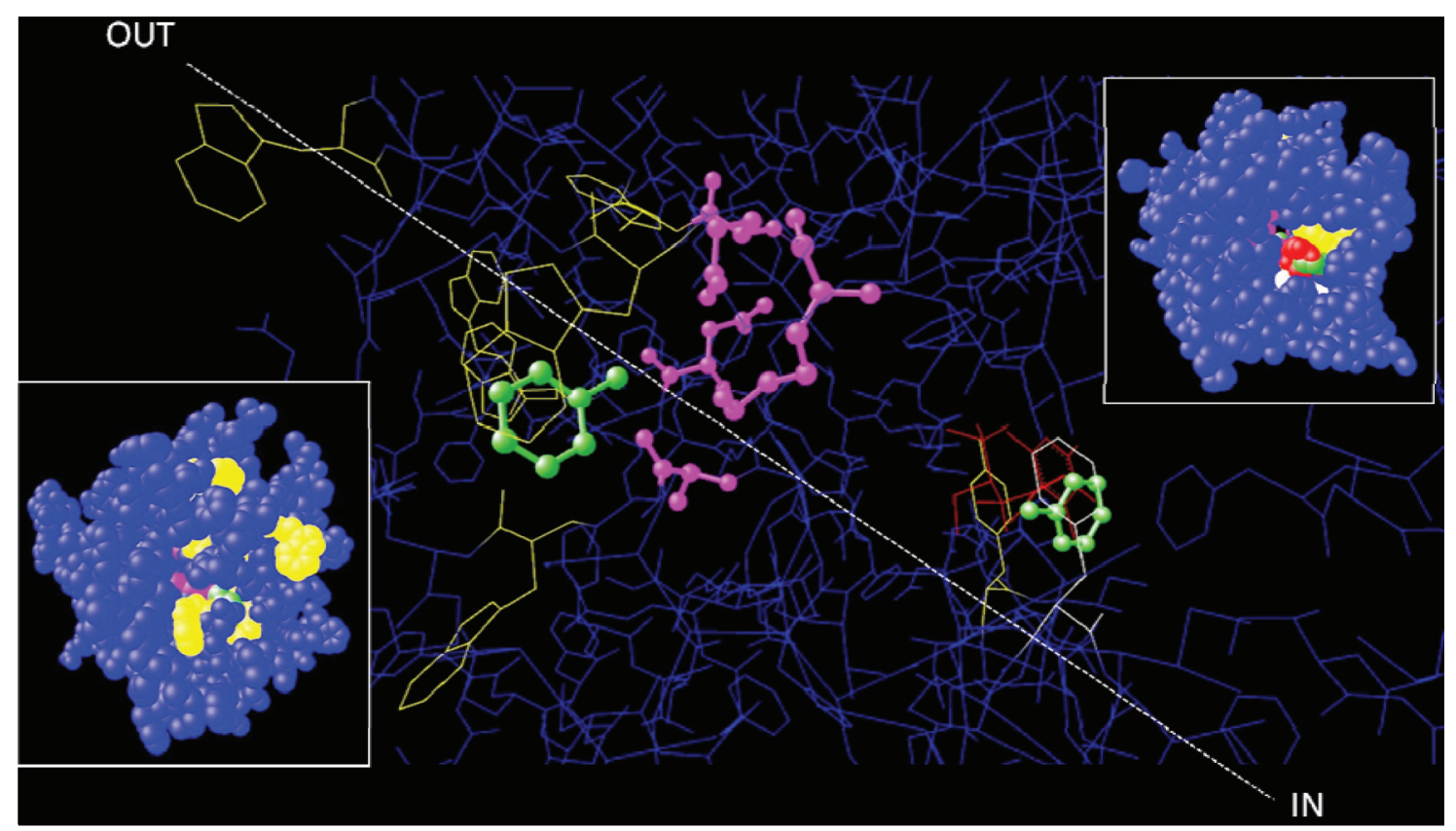

Figure 3 Docking of toluene in the inner pore of $\mathrm{Na}_{v} 1.5$ channel. Either the tryptophan-rich outer lip (to the left) or the LABS (to the right) is visited by the ligand (green ball and sticks) in equal proportions as to binding strength and solved poses. Colors: pore is blue; the tryptophan-rich outer lip is yellow (B:Trp6I, C:Trp62, D:Trp62), with the docked lidocaine in red of Tikhonov's model at the LABS (D:Phe84 yellow and D:Tyr9l white) in close proximity to one of the two docked toluene moieties in green. The entry path from the extracellular space, white line (upper left-hand side) towards inside (lower right-hand side) goes through the sodium-selective DEKA ring of the pore in open state (magenta, center). The lower left-hand and upper right-hand corners display two space fill views (in reduced scale and same color code) of the outer and inner vestibules, respectively.

this decision is two-fold: (i) the helical prediction is most reliable because the principles on which its construction is based mostly depend on inner-chain neighborhood atomic interactions; and (ii) the very low sequence homology where functional coincidence is rarely met, ie, random coincidence of matching target-template pairs cannot be ruled out in the threaded residue pairs. In addition, the identification of the known DEKA motif with its location and various loop segments between the helices assisted the manual alignment procedure (Table 3). Unfortunately, since the template with its open state and pore features is still unique among the crystal channel proteins (Table 1), neither consensus nor comparative protein modeling is amenable. On the one hand, this lack of alternatives eases the model building but at the cost of full dependency on a single backbone. Our structure modeling approach is exhaustively described elsewhere. ${ }^{22}$

Blind docking addresses the problem of finding ligand conformations and positions at the binding site without knowing the final solution provided by X-ray or nuclear magnetic resonance analyses. Clustering free energies of binding requires sampling ligand poses according to their receptor affinities (lowest energy scores). The bibliographic and experimental knowledge gained in earlier docking studies with Insight II, Ludi, FlexX, Autodock, and MOE, was invaluable in helping us meticulously select the adequate software. ${ }^{23-26}$

The blind docking was conducted using Autodock 3 because its calibration set embraces relevant binding patterns seen on alkylaryl moieties such as toluene. ${ }^{27,28}$ Particularly, hydrophobic contacts, $\pi-\pi$ bonding, and edge-to-face contacts are expected to play a pivotal role in alkylbenzene binding rather than the commonly seen hydrogen bonding or ion bridges. ${ }^{29,30}$ The ligand's atomic partial charges were calculated by the Gasteiger approach under VEGA while the receptor was prepared, ${ }^{31}$ and charges on polar hydrogen atoms were calculated with Autodock tools. ${ }^{32}$

\section{Electrophysiological recording in oocytes}

Oocytes were placed in a $1.6-\mathrm{mL}$ recording chamber and continuously superfused with a barium-containing solution at a flow rate of approximately $1 \mathrm{~mL} \mathrm{~min}$. Two electrode voltage-clamp recordings were performed at room temperature (20-22 ${ }^{\circ} \mathrm{C}$ ) using an OC-725C amplifier (Warner, New Haven, CT). Electrodes were pulled on a horizontal puller (P-97, Sutter Instruments, Novato, CA). Agarose-cushion electrodes filled with $3 \mathrm{M} \mathrm{KCl}$ were used to achieve a final resistance of 0.6 to $1.2 \mathrm{M} \Omega .^{33}$ Sodium current signals were digitized at 
Table 2 Multiple alignments of amino acid sequences with CLUSTAL $\times$ (version I.83). Legend: In the second last row the three characters “*”, “"”, and “.” symbolize identical, highly or weakly conserved amino acids, respectively. Blanks mean “no homology at all.” Dashes - indicate deletion of residues

\begin{tabular}{|c|c|c|}
\hline & Helix A1 & \\
\hline 1LNQ Template & 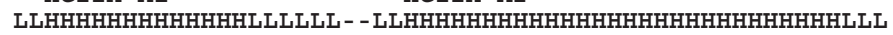 & \\
\hline & $:: *: *::: \quad: \quad * \quad * *:: x_{0 * *}^{*} \quad{ }^{*}: * * *:$ & \\
\hline & TVSLYWTFVTIATVGYGDYSP - -STPLGMYFTVTLIVLGifLPATIVLAVIIYGTA & \\
\hline Nav 1.5 & FDSFAWAFLALFRLMTQDCWERLYQKIYMIFFMLVIFLGSFYLVNLILAVVAMAYE & 56 \\
\hline Nav 1.4 & 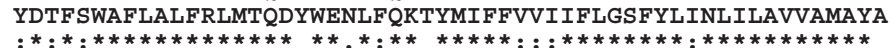 & 56 \\
\hline Model sec str & 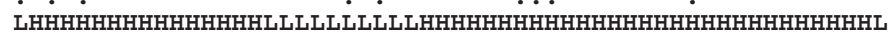 & \\
\hline & $\begin{array}{l}(4) \\
\text { Helix B1 }\end{array}$ & \\
\hline 1LNQ Template & 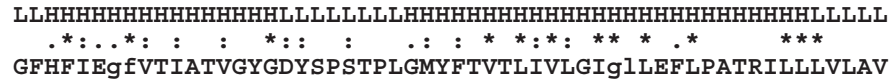 & \\
\hline Nav 1.5 & MMDFFHAFLIIFRILCGEWIETMWDSLCLLVFLLVMVIGNLVVLNLFLALLLSSFS & 113 \\
\hline Nav 1.4 & 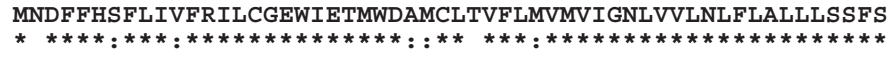 & 113 \\
\hline Model sec str & LHHHHHHHHHHHHHHHLLLLLLLLLLHHHHHHHHHHHHHHHHHHHHHHHHHHHHHL & \\
\hline & $\begin{array}{llll}(6) & & (8) \\
\text { Helix C1 } & (7) & \text { Helix C2 } & \text { Helix C3 }\end{array}$ & \\
\hline 1LNQ Template & 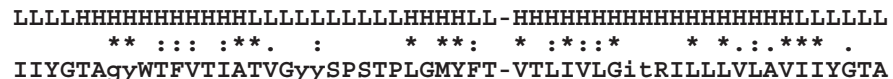 & \\
\hline Nav 1.5 & FDNVGAGYLALLQVATFKGWMDIMYLYMY IYFVIFIIFGSFFTLNLFIGVIIDNFN & 179 \\
\hline Nav 1.4 & YDNVGLGYLSLLQVVATFKGWMDIMYLYMYLYFVIFIIFGSFFTLNLFIGVIIDNFN & 178 \\
\hline Model sec str & $\begin{array}{l}: * * * * * *:: * * * * * * * * * * * * * * * * * *: * * * * * * * * * * * * * * * * * * * * * * * *) \\
\text { LLLLHHHHHHHHHHLLLLLLLLLLLHHHHHHHHHHHHHHHHHHHHHHHHHHHL }\end{array}$ & \\
\hline & 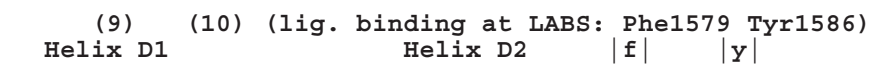 & \\
\hline 1LNQ Template & 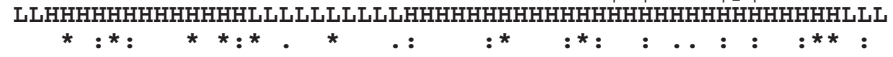 & \\
\hline & GFHFIESLYWTFVIATVGYGDYSPSTPLGMYFTVTLIVLGIGTFAVAVERLLEFL- & \\
\hline Nav 1.5 & FQTFANSMLCLFQITTSAGWDGLLSAVGILFFTTYIIIS fLIVVNMY IAIILENFS & 224 \\
\hline Nav 1.4 & 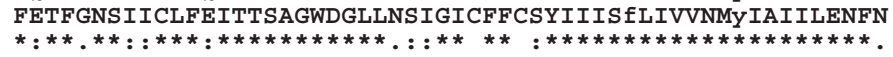 & 224 \\
\hline Model sec str & 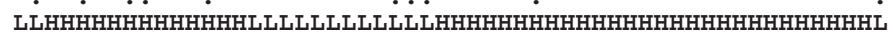 & \\
\hline
\end{tabular}

Row I: Labels of omitted segments (I) to (I0) loops of template.

Row 2: Labels of secondary structures of template.

Row 3: Secondary structure of template: Helical; Loops (not helical).

Row 4: Homology scores of rows 5 and 6.

Row 5: Sequence of template; PDB entry: ILNQ (see below*).

Row 6: Sequence of target Nav 1.5 by our group (see below**).

Row 7: Sequence of target Nav 1.4 by Tikhonov, Bruhova, and Zhorov.

Row 8: Homology scores of rows 6 and 7.

Row 9: Predicted secondary structure of target: Helical; Loops (not helical).

Notes: Two adjacent lower-case letters mark the insertion of omitted segments, cf. Table 3.); Lower-case letters mark the predicted interaction sites upon docking.

a sampling rate of $10 \mathrm{kHz}$ by an analog-to-digital converter (Digidata 1200, Axon Instruments, Foster City, CA) and stored on a computer for analysis with pClamp software (Version 7.01, Axon Instruments, Foster City, CA). Sodium currents $\left(\mathrm{I}_{\mathrm{Na}}{ }^{+}\right)$were elicited by step depolarizations from a holding potential of $-110 \mathrm{mV}$ at $0.1 \mathrm{~Hz}$ unless otherwise indicated. The amplitude of expressed $\mathrm{I}_{\mathrm{Na}}{ }^{+}$was typically 1-10 $\mu$ A. Only oocytes with peak $\mathrm{I}_{\mathrm{Na}}{ }^{+}$lower than $7 \mu \mathrm{A}$, were used, to minimize voltage-clamp errors. ${ }^{34}$ Current-voltage relationships were determined from peak currents elicited by $30-\mathrm{ms}, 10-\mathrm{mV}$ steps from a holding potential of $-120 \mathrm{mV}$ up to $+50 \mathrm{mV}$.

\section{Results}

Our results show that toluene blocks human cardiac sodium and skeletal muscle channels as a function of concentration and in a use- and frequency-dependent manner, and that site of action may be related to the LABS, particularly in Phe1579 (Figure 2). ${ }^{35}$

The focus of our computed work is the central cavity of the inner pore belonging to the alpha subunit where specific cation passage takes place. ${ }^{10,36}$ Prior to modeling, we inspected the 3D-model pool at ftp.wwpdb.org but could not find a suitable structure of a human cardiac $\mathrm{Na}^{+}$channel (Table 1).

Lacking crystallographic data of a proper sodium channel (Table 1), and despite low homology between sodium and potassium channels (sequence identity 14\%), the crystal structure of a potassium channel was chosen as a template by Tikhonov and colleagues ${ }^{37}$ to generate their 3D-model of $\mathrm{Na}_{\mathrm{v}}$ 1.4. In need of a channel structure in the open state, we 
Table 3 Primary sequence inspections of the eight loop segments excluded from the 3D model due to much shorter lengths on the backbone of the template (ILNQ)

\begin{tabular}{lllllllll}
\hline IsoformsILoops & $\mathrm{I}$ & 2 & 3 & 4 & 5 & 6 & 7 & 8 \\
\# aa $\mathrm{Na}_{\mathrm{v}} \mathrm{I} .4$ & 7 & 33 & 259 & 420 & 17 & 219 & 28 & 234 \\
\# aa $\mathrm{Na}_{\mathrm{v}} \mathrm{I} .5$ & 7 & 145 & 318 & 458 & 17 & 219 & 27 & 240 \\
Charge $\mathrm{Na}_{\mathrm{v}}$ I.4 & $\mathrm{I}+$ & $6-$ & $5-$ & $28-$ & $3-$ & $13+$ & $3-$ & $12-$ \\
Charge $\mathrm{Na}_{\mathrm{v}} \mathrm{I} .5$ & $\mathrm{I}+$ & $\mathrm{I}-$ & $4-$ & $20-$ & $3-$ & $12+$ & $\mathrm{I}-$ & $17-$ \\
GRAVY-I.4 & +0.8 & -2.0 & +0.3 & -0.1 & -1.7 & +0.4 & -0.9 & -0.6 \\
GRAVY-I.5 & -0.6 & -1.2 & +0.1 & -0.3 & -1.6 & +0.4 & -0.8 & -0.7 \\
\hline
\end{tabular}

generated a 3D model of $\mathrm{Na}_{\mathrm{v}} 1.5$ in an analogous approach (Tables 2 and 3). ${ }^{21,22}$ The other crystal structures listed in Table 1 are less suitable templates in so far as they constitute $\mathrm{K}^{+}$channels in a closed state forming a highly symmetrical tetrameric protein in the cell membranes.

In order to explain our experimental findings, ${ }^{13,14}$ on a molecular level, we conducted in silico ligand docking studies into the central pores of $\mathrm{Na}_{\mathrm{v}} 1.4$ and 1.5 under AD3. The sequences of both 3D models possess high homology (sequence identity: $84 \%$ ). ${ }^{38}$ After successful validation of two crystallographic binding poses (PDB entries: 2MCP, 1J95), ${ }^{39}$ and the docked BTX and lidocaine into the 3D models of $\mathrm{Na}_{\mathrm{v}} 1.4$, respectively $\mathrm{y}^{10,36,37,40}$ we applied the same docking and scoring protocols of AD3 to search the energetically optimal position of toluene in our 3D model of $\mathrm{Na}_{\mathrm{v}} 1.5$. AD3 is capable of efficiently sampling very large search spaces. The partial charges as well as the positively charged nitrogen atom type of BTX and lidocaine were treated adequately (see AD3 manual). ${ }^{41}$ Particularly good results were obtained for PDB entry 1J95 (Table 2), with a co-crystallized substituted quaternary ammonium derivative. ${ }^{39}$ The way it contacts two aromatic residues, Tyr and Trp, reflects cation $-\pi$ electron bonding, a priceless asset for blind docking of cationic ligands like our test ligand lidocaine. ${ }^{42}$ The primary sequence analysis of the 224 amino acids of $\mathrm{Na}_{\mathrm{v}} 1.4$ and 1.5 shows that the former has a plus of 10 negative charges while the latter has a plus of just 8 . The site of $\mathrm{Na}_{\mathrm{v}} 1.5$ is slightly more lipophilic than that of $\mathrm{Na}_{\mathrm{v}} 1.4$ (Table 3). The grand average of hydropathicity score yields +1.2 for $\mathrm{Na}_{\mathrm{v}} 1.4$ and +1.4 for $\mathrm{Na}_{\mathrm{v}} 1.5$, respectively. ${ }^{15}$ To generate the 3D-model most parts of the loop segments between the pore helices had to be removed from the template sequence (1LNQ) to reflect best the number of positions on the helical wheels and the

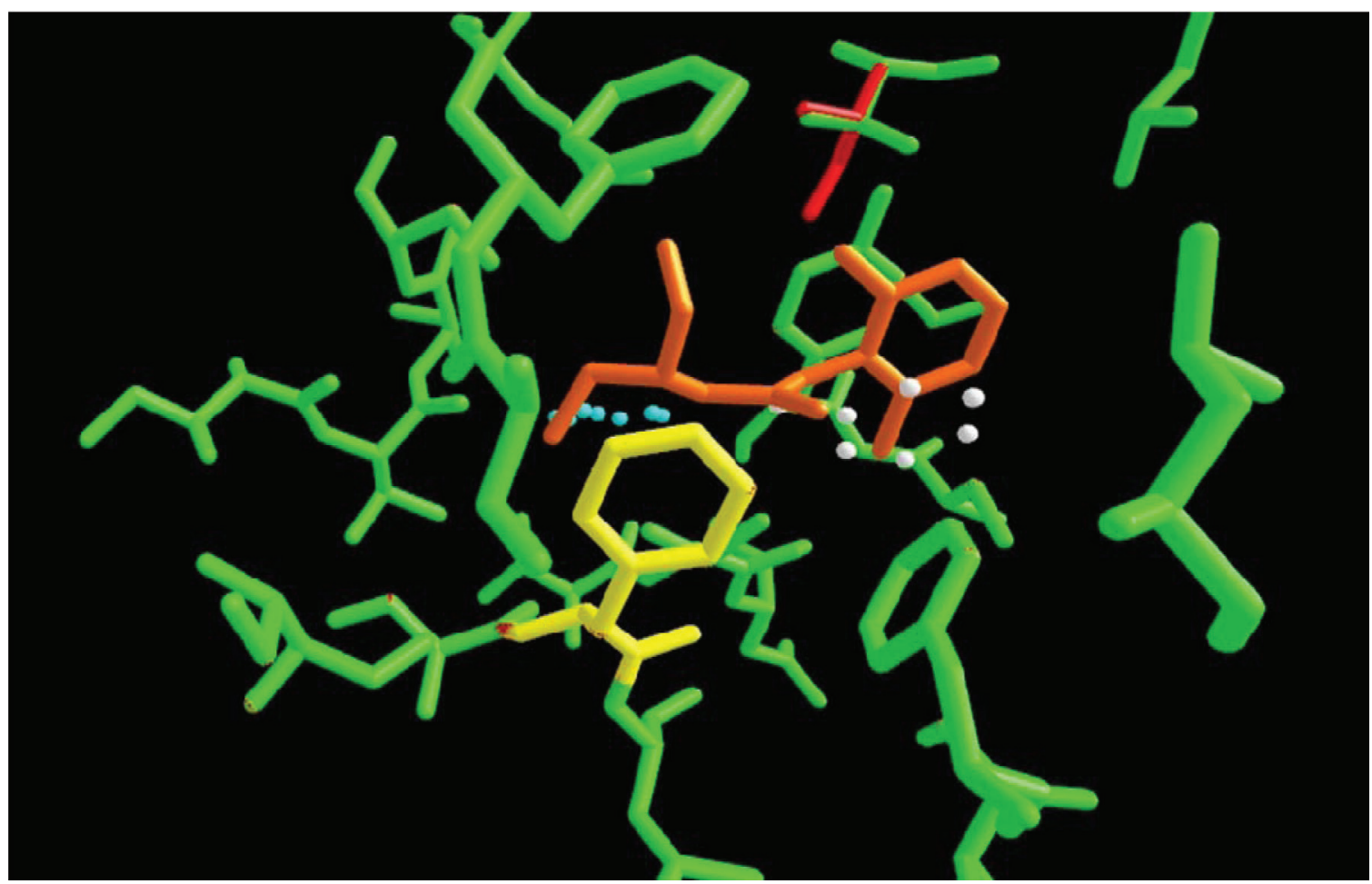

Figure 4 Consensus molecular model of both isoforms, $\mathrm{Na}_{v} \mathrm{I} .4$ (red) and $\mathrm{Na}_{v} \mathrm{I} .5$ (green). The docked ligand lidocaine (orange) and toluene in white and blue dots (bonds suppressed for better viewing). The white toluene ligand is in that position only with the green model, and the blue ligand is only with the red model. The red model is superimposed by the green model to visualize structural differences. Due to the change in $\mathrm{VdW}$ volume toluene is pushed aside by steric hindrance of isoleucine (red) on $\mathrm{Na}$ 1.4 compared to the shorter side chain of valine (green) on Nav I.5 (cf. Table 4). The ligand interaction is a face-edge-face interaction. The two modes of molecular interaction between toluene and Phe- 1879 (yellow) of the $\mathrm{Na}^{+}$channel is as follows: I.- Edge-face interaction (blue-yellow); 2.-Sandwinch $\pi$ - $\pi$ interaction (white-yellow). The Phenylalanine (yellow) belongs in this position to both channels isoforms (green and red). 
homology (Table 2). ${ }^{21,22}$ A survey of the chemical information thus lost is given in Table 3. Reported changes in total number of amino acids, charges and hydrophobicity may account for the observed sensitivity difference between $\mathrm{Na}_{\mathrm{v}} 1.4$ and 1.5 (Table 3). This conclusion is in line with our sequence and model inspection (Table 2; Figure 4) of both isoforms. No major structural differences that could affect docking affinities were detected at the contact zones after successful docking of the toluene ligand at the outer tryptophan-rich lip or inner LABS (Table 4). The latter vestibule forms a lipophilic pocket within a radius of $0.4 \mathrm{~nm}$ around the ligand with C:Phe59, C:Phe91, D:Phe84, and D:Tyr91. The only difference between $\mathrm{WT} \mathrm{Na}_{\mathrm{v}} 1.4$ and 1.5 constitutes a conservative valine-isoleucine exchange whose sequence position is underlined in Table 2 (first sequence row: A:Tyr86, A:Leu87, A:VAL88ILE, A:Asn89; see also Table 4; Figure 4).

A bias was identified in that binding apparently fell short on surface-exposed aromatic pockets (exposed A:Trp48 next to buried A:Trp62) or surfacing B:Trp66 and D:Trp62). The scoring function can better evaluate residue locations deeper in the cleft with contributions from all sides $(C$ : Trp62 and D: Phe76). To avoid this artifact (note: true pore is embedded in a multi-unit complex) and to study side chain flexibility (note: the receptor model is simplified as a rigid body), we systematically modified dihedral angles of relevant residues to either orient inwards (A:Trp48 and D:Trp62) or accommodate the ligand for user-defined start positions of docking (A:Trp48 with A:Trp62; C:Trp62 with D:Phe76). With the resulting minor affinity changes - like a paddle on its axis - the ligand orients accordingly and binds slightly with Trp62 at a stacking distance by side chain rotation into calyxlike poses. The ligand, however, appeared laterally buried, a phenomenon generally ascribed to induced fit mechanism at a true binding site (Figure 3). ADT displays the solved poses in two main RMS clusters. One is located at the LABS near the cytosolic entrance to the central pore and the other one at the TRP-rich lip of the extracellular mouth (Figure 3). The DEKA locus in the middle section of the channel in Figure 3 is not concerned, because it is away of possible interaction. The ligand's aromatic ring forms hydrophobic contacts by edge-to-face orientation and stacking $\pi$ - $\pi$ motifs with either the tryptophan-rich lip on the outer vestibule or Tyr91 of the LABS (Figure 4). Both docked poses yield practically the same binding energies and number of docking solutions (Table 4). The estimated $\mathrm{IC}_{50}$ value of the LABS pose comes closer to the reported experimental value of $274[\mu \mathrm{M}]$ than any other docked poses with values of 760 and more. ${ }^{13}$

\section{Discussion}

Our in silico study shows that toluene does not bind at the DEKA motif but probably at the outer tryptophane-rich vestibule of the inner pore of the sodium channel protein-complex or at the LABS, though we could not investigate other possible interaction sites due to missing structural data of the entire complex with its cooperating subunits.

In view of the fact that the LABS is quite important in sodium channels, the site has many interaction mechanisms besides those discussed here (such as hydrophobic,

Table 4 Listing of experimental and theoretical results

\begin{tabular}{|c|c|c|c|}
\hline \multirow[t]{2}{*}{ Change in amino acids } & \multirow{2}{*}{$\begin{array}{l}\text { Striated muscle } \mathrm{Na}_{v} \mathrm{I} .4 \mathrm{WT} \\
\text { Phenylalanine }\end{array}$} & \multirow{2}{*}{$\frac{\mathrm{Na}_{\mathrm{v}} \mathrm{I} .4 \text { mutant LABS: F I579A }}{\text { Alanine }}$} & \multirow{2}{*}{$\frac{\text { Cardiac } \mathrm{Na}_{\mathrm{v}} \text { I.5 WT }}{\text { Phenylalanine }}$} \\
\hline & & & \\
\hline $\begin{array}{l}\text { Observed channel blocking } \\
\text { effects; measured as } \\
\text { milimolar } \mathrm{IC}_{50}(*)\end{array}$ & $\begin{array}{l}\text { Effects present; } 3[\mathrm{mM}] \text { ie, ten times } \\
\text { less sensitive than } \mathrm{Na}_{v} \text { I.5WT }\end{array}$ & Effects abolished & $\begin{array}{l}\text { Effects present; predicted } \\
0.3 \text { [mM] (in-silico model); } \\
274 \text { uM (experimental) }\end{array}$ \\
\hline $\begin{array}{l}\text { Prediction of docked poses } \\
\text { and computed millimolar } \\
\text { inhibition constant } \mathrm{K}_{i}: 0.3 \mathrm{mM}\end{array}$ & $\begin{array}{l}\text { Docked poses at LABS and at } \\
\text { Trp-rich outer lip in equal } \\
\text { proportions. } \mathrm{Ki}>0.3 \text { [mM] } \\
\text { and reaches the upper limit of the } \\
\mathrm{K} \text { estimation scale. Average binding } \\
\text { energy } 4.2 \mathrm{KJ} / \mathrm{Mol}\end{array}$ & $\begin{array}{l}\text { Complete loss of specific binding at } \\
\text { LABS; but diffuse poses on Trp-rich } \\
\text { outer lip with } \mathrm{Ki}=>0.4[\mathrm{mM}] \\
\text { Average binding energy } 3.4 \mathrm{KJ} / \mathrm{Mol}\end{array}$ & $\begin{array}{l}\text { Docked poses at LABS and at } \\
\text { Trp-rich outer lip in equal } \\
\text { proportions. } \mathrm{Ki}=0.28 \text { [mM]; } \\
\text { Average binding energy } \\
4.1 \mathrm{KJ} / \mathrm{Mol}\end{array}$ \\
\hline $\begin{array}{l}\text { Difference between } \mathrm{Na}_{v} \mathrm{I} .4 \\
\text { and } \mathrm{Na}_{v} \mathrm{I} .5 \text { in LABS region } \\
(\mathrm{r}=0.8 \mathrm{~nm})\end{array}$ & $\begin{array}{l}\text { A:Cys6I; A:lle88; cf. Table } 2 \text { with } \\
\text { underlined isoleucine in bold face }\end{array}$ & $\begin{array}{l}\text { A:Cys6I; } \\
\text { A:lle88; }\end{array}$ & $\begin{array}{l}\text { A:Tyr6I - no effect; } \\
\text { A:Val88 - small effect on docking } \\
\text { due to steric hindrance (cf. Figure 4) }\end{array}$ \\
\hline $\begin{array}{l}\text { Difference between } \mathrm{Na}_{\vee} \mathrm{I} .4 \\
\text { and } \mathrm{Na}_{v} \mathrm{I} .5 \text { in Trp rich region } \\
(\mathrm{r}=0.8 \mathrm{~nm})\end{array}$ & $\begin{array}{l}\text { A:Tyr6I; A:Tyr } 43 \text { : all other residue } \\
\text { changes in sequence are too far } \\
\text { away from lig }\end{array}$ & $\begin{array}{l}\text { A:Tyr6I; } \\
\text { A:Tyr43; }\end{array}$ & $\begin{array}{l}\text { A:Cys6I; - no effect; } \\
\text { A:Phe43; - no effect; side chain not } \\
\text { oriented to ligand }\end{array}$ \\
\hline
\end{tabular}

Notes: The potencies of enzyme inhibitors are often reported in terms of $\mathrm{IC}_{50}$ values rather than $\mathrm{K}_{\mathrm{i}}$ values. The former indicates the inhibitor concentration to reduce the activity by half. It is important to recognize that $\mathrm{IC}_{50}$ depends on the substrate concentration used in the experiment and subsequently is not (a) constant. 
van der Walls), the true site (F1579 in $\mathrm{Na}_{\mathrm{v}} 1.4$ and F1879 in $\mathrm{Na}_{\mathrm{v}}$ 1.5) may be related to other complex interactions with the surrounding amino acids, eg, Y1586 and V1582.43,44

Despite this limitation there is sufficient computational evidence to conclude that: the final pose docked at the inner pore entrance yields a consistent picture showing that by occluding the channel, toluene eliminated electric conductance, because it lacks - as do many reported blockers - the continuous string of oxygen atoms necessary for blocking typical channel conductance. ${ }^{10}$ In addition, both cleft and the outer vestibule are more hydrophilic and filled with water, whereas the helical segments are lined by predominantly hydrophobic residues for their site in the membrane. AD3 is especially suited (cf. training set) to recognize and cope with such ionic, polar and hydrophobic interactions. Hence, it is more likely that toluene permeates the lipid layers of excitable cells and reaches the cytosolic channel entry to dock to the known LABS.

In view of the earlier experiments our present in silico docking study of toluene with the structure model of $\mathrm{Na}_{\mathrm{v}}$ 1.4 channel in the open state helps to formulate a working hypothesis on a molecular level for possible interactions with the pore amino acids and to design new electrophysiological experiments in future. In conclusion, the present in silico result is in concert with our experimental observations and supports the literature that shows that toluene has cardiotoxic effects, in addition to its known heptotoxic effects. ${ }^{45,46}$

\section{Acknowledgments}

This work was completed with the assistance of the following grants: BUAP-VIEP grant \#SASE-SAL-08-G, and CONACyT \# 48294-M to EMSS, CONACyT \# 2007/526392 to TS, as well as CONACyT PhD Scolarship \# 175906 to EMM.

\section{References}

1. Grant AO. Envolving concepts of cardiac sodium channel tunction. J Cardiovas Electrophysiol. 1990;1:53-67.

2. Adelman JP. Proteins that interact with the pore-forming subunits of voltage-gated ion channels. Curr Op Neurobiol. 1995;5:286-295.

3. An RH, Bangalore R, Rosero SZ, Kass RS. Lidocaine block of LQT-3 mutant human $\mathrm{Na}^{+}$channels. Circ Res. 1996;79:103-108.

4. Harris L, Downar E, Shaickh N, Chen T. Antiarrhythmic potential of chloroquine:New use for an old drug. Can J Cardiology. 1998; 4:295-300.

5. Orta-Salazar G, Bouchard RA, Morales-Salgado F, Salinas-Stefanon EM. Inhibition of cardiac $\mathrm{Na}^{+}$current by primaquine. Br J Pharmacol. 2002;135:751-763.

6. Sanchez CJA, Salinas SE, Torres JJ, Benavides HDE, Navarro PRA. Blockade of currents by the antimalarial drug chloroquine in feline ventricular myocytes. J Pharmacol Exp Ther. 2001;297:437-445.

7. Lipkind G, Fozzard HA. Molecular modeling of local anesthetic drug binding by voltage-gated sodium channels. Mol Pharmacol. 2005;68:1612-1622.
8. Hockerman GH, Johnson BD, Abbott MR, Scheuer T, Catterall WA. Molecular determinants of high affinity phenylalkylamine block of L-type calcium channels in transmembrane segment IIIS6 and the pore region of the Alpha1 subunit. J Biol Chem. 1997;272: 18759-18765.

9. Bénitah J-P, Ranjan R, Yamagishi T, Janecki M, Tomaselli GF, Marban E. Molecular motions within the pore of voltage-dependent sodium channels. Biophys J. 1997;73:603-613.

10. Tikhonov DB, Zhorov BS. Modeling P-loops domain of sodium channel: homology with potassium channels and interaction with ligands. Biophys J. 2005;88:184-197.

11. Bransburg-Zabary S, Nachliel E, Gutman M. A fast in silico simulation of ion flux through the large-pore channel proteins. Biophys $J$. 2002;83:3001-3011.

12. Khan A, Romantseva L, Lam A, Lipkind G, Fozzard H. Role of outer ring carboxylates of the rat skeletal muscle sodium channel pore in proton block. J Physiol (Lond). 2002;543:71-84.

13. Cruz LS, Orta-Salazar G, Gauthereau MY, Millan-Perez Peña L, Salinas-Stefanon EM. Inhibition of cardiac sodium currents by toluene exposure. Br J Pharmacol. 2003;140:653-660.

14. Gauthereau MY, Salinas-Stefanon EM, Cruz LS. A mutation in the local anaesthetic bindig site abolishes toluene effects in sodium channels. Eur J Pharmacol. 2005;528:17-26.

15. Gasteiger E, Hoogland C, Gattiker A, et al. Protein identification and analysis tools on the ExPASy Server. In: Walker JM, editor. The Proteomics Protocols Handbook. 1st ed. Humana Press; 2005. p. 571-607.

16. Kabsch W, Sander C. Dictionary of protein secondary structure: pattern recognition of hydrogen-bonded and geometrical features. Biopolymers. 1983;22:2577-2637.

17. Jones DT. Protein secondary structure prediction based on positionspecific scoring matrices. J Mol Biol. 1999;292:195-202.

18. Cuff JA, Barton GJ. Evaluation and improvement of multiple sequence methods for protein secondary structure prediction. Proteins. 1999;34:508-519.

19. Frishman D, Argos P. Incorporation of non-local interactions in protein secondary structure prediction from the amino acid sequence. Protein Eng. 1996;9:133-142.

20. Muñoz V, Serrano L. Development of the multiple sequence approximation within the AGADIR model of alpha-helix formation: comparison with Zimm-Bragg and Lifson-Roig formalisms. Biopolymers. 1997;41:495-509.

21. Jiang Y, Lee A, Chen J, Cadene M, Chait B, Mackinnon R. Crystal structure and mechanisms of a calcium-gated potassium channel. Nature. 2008;417:515-516.

22. Scior T, Wahab A. Structure prediction of proteins with very low homology: A comprehensive introduction and a case study on aminopeptidase. In: Stanley P. Kaplan, editor. Drug Design Research Perspectives. Nova Science Publishers; 2007. p. 675-708.

23. Coupez B, Lewis RA. Docking and scoring - theoretically easy, practically impossible? Curr Med Chem. 2006;13:2995-3003.

24. Stoermer MJ. Current status of virtual screening as analysed by target class. Med Chem. 2006;2:89-112.

25. Campbell S, Gold N, Jackson R, Westhead DR. Ligand binding: functional site location, similarity and docking. Curr Op Struct Biol. 2003;13:389-395.

26. McConkey BJ, Sobolev V, Edelman M. The performance of current methods in ligand-protein docking. Curr Sci. 2002;83:845-856.

27. Morris GM, Goodsell DS, Halliday RS, et al. Automated docking using a Lamarckian genetic algorithm and an empirical binding free energy function. J Comput Chem. 1998;19:1639-1662.

28. Buzko OV, Bishop AC, Shokat KM. Modified AutoDock for accurate docking of protein kinase inhibitors. J Comput Aided Mol Des. 2002;16:113-127.

29. Jennings WB, Farrell BM, Malone JF. Attractive intramolecular edge-to-face aromatic interactions in flexible organic molecules. Arch Chem Res. 2001;34:885-894. 
30. Meyer EA, Castellano RK, Angew FD. Interactions with arenes interactions with aromatic rings in chemical and biological recognition. Chem Int Ed. 2003;42:1210-1249.

31. Gasteiger J, Marsili M. Prediction of proton magnetic resonance shifts: the dependence on hydrogen charges obtained by iterative partial equalization of orbital electronegativity. Org Magn Resonance. 1981;15:360.

32. Weiner S, Kollman P, Nguyen D. An all atom force field for simulations of proteins and nucleic acids. J Comput Chem. 1986;7:230-252.

33. Schreibmayer W, Lester HA, Dascal N. Voltage clamping of Xenopus laevis oocytes utilizing agarose-cushion electrodes. Pflügers Arch-Eur Physiol. 1994;426:453-458.

34. Li AR, Tsushima RG, Himmeldirk K, Dime DS, Backx PH. Local anesthetic anchoring to cardiac sodium channels. implications into tissue-selective drug targeting. Circ Res. 1999;85:88-98.

35. Ragsdale DS, McPhee JC, Scheuer T, Catterall WA. Molecular determinants of state-dependent block of $\mathrm{Na}^{+}$channels by local anesthetics. Science. 1994;265:1724-1728.

36. Yamagishi T, Li RA, Hsu K, Marbán E, Tomaselli GF. Molecular architecture of the voltage-dependent Na channel: Functional evidence for $\alpha$ helices in the pore. $J$ Gen Physiol. 2001;118:171-182.

37. Tikhonov D, Bruhova I, Zhorov BS. Atomic determinants of statedependent block of sodium channels by charged local anesthetics and benzocaine. FEBS Lett. 2006;580:6027-6032.

38. Gellens ME, George AL, Chen L, et al. Primary structure and functional expression of the human cardiac tetrodotoxin-insensitive voltage-dependent sodium channel. Proc Natl Acad Sci U S A. 1992;89:554-558.
39. Padlan E, Cohen G, Davies D. Refined crystal structure of the Mc/ Pc603 Fab-phosphocholine complex at 3.1 angstroms resolution. PDB Databank. 1992. Cited on Nov 26, 2008. Available from: ftp://ftp. wwpdb.org.

40. Tikhonov DB, Zhorov BS. Sodium channel activators: model of binding inside the pore and a possible mechanism of action. FEBS Lett. 2005;579:4207-4212.

41. Lipkind G, Fozzard HA. Molecular modeling of local anesthetic drug binding by voltage-gated sodium channels. Mol Pharmacol. 2005;68:1611-1622.

42. Scrutton N, Raine A. Cation-pi bonding and amino-aromatic interactions in the biomolecular recognition of substituted ammonium ligands. Biochem J. 1996;319:1-8.

43. Christopher A, Eastwood A, Dougherty D, Horn R. Electrostatic contributions of aromatic residues in the local anesthetic receptor of voltage-gated sodium channels. Circ Res. 2008;102:86-94.

44. Lipkind GM, Fozzard HA. Molecular modeling of interactions of dihydropyridines and phenylalkylamines with the inner pore of the L-type Ca2+ channel. Mol Pharmacol. 2003;63:499-511.

45. Chapman D, Michener S, Powis G. Metabolism and covalent binding of [14C]toluene by human and rat liver microsomal fractions and liver slices. Drug Metab Dispos. 1995;18:929-936.

46. Hanioka H, Hammamura M, Kakino K, et al. Dog liver microsomal P450 enzyme-mediated toluene biotransformation. Xenobiotica. 1995;25:1207-1217. 
